\title{
Bio-inspired Computation Technique to Chance Constrained Fuzzy Goal Programming Model for Resource Allocation in Farm Planning
}

\author{
Debjani Chakraborti \\ Narula Institute of Technology \\ Dept. of Mathematics \\ Kolkata, West Bengal
}

\begin{abstract}
This paper describes the efficient use of a Bio-inspired computation technique to fuzzy goal programming (FGP) formulation of land allocation problems having chance constraints for optimal production of different seasonal crops in agricultural system.

In the proposed approach, utilization of total cultivable land, different productive resources, achievement of target levels of the production of seasonal crops and expected profit from the farm are fuzzily described.

In the model formulation of the problem, the concept of tolerance membership functions in fuzzy sets for measuring the degree of optimality of crops-production by utilizing the productive resources is considered.

In the solution process, achievement of the defined membership goals to the highest degree (unity) to the extent possible on the basis of priorities is determined by employing genetic algorithm (GA) scheme in the decision making environment.
\end{abstract}

A case example is considered to demonstrate the approach.

\section{Keywords}

Fuzzy Goal Programming; Chance Constrained Programming; Fuzzy Stochastic Programming; Genetic Algorithms; Membership Function.

\section{INTRODUCTION}

Owing to the increase of health awareness in the technological affluent society along with alarming rate of increase of human population in the past few years, worldwide alertness for sustainable growth of agricultural products to meet the primary need 'food' has taken place in the recent years. Demand for the requirement of food grains is increasing but the land for cultivation is limited. So proper planning is essential for the agricultural production system.

Among all the species, plants are the primitive species, and the major constituent of any kind of plant is water. It is thought that domestication of plants went on as far as 7000 B.C. and plant-based food production system through forest gardening, the world's oldest known form of agriculture, was started as far back as 5200 BC. Actually, the development of agriculture made human civilization possible.

Biodiversity has enabled farming systems to evolve ever since agriculture was first developed some 10,000 years ago in regions across the world. Worldwide there is now a huge diversity of agricultural systems ranging, for example, from rice paddies of Asia, to dryland pastoral systems of Africa, and hill farms in the mountains of South America. Biodiversity is the source of the plants and animals that form the basis of agriculture and the immense variety within each crop and livestock species. Countless other species contribute to the essential ecological functions upon which agriculture depends, including soil services and water cycling. However, the Earth's biodiversity is being lost at an alarming rate, putting in jeopardy the sustainability of ecosystem services and agriculture, and their ability to adapt to changing conditions. The conservation and sustainable use of biodiversity is essential for the future of agriculture and humanity.

In an agricultural planning situation, optimal production of seasonal crops highly depends on proper allocation of land and adequate supply of productive resources for cultivating the crops in different seasons of the planning period.

Since, the agricultural planning problems involve multiplicity of objectives, goal programming (GP) [1] as a prominent tool for multiobjective decision analysis has been widely used to farm management problems. The deep study in this area has been surveyed by Glen [2] in the past. The use of GP to farm planning has also been studied by Pal and Basu [3] in the past.

However, the main weakness of GP formulation of real-life problems is that the different resource parameters involved with the problems need to be precisely defined. But, in most of the decision situations, they are found to be imprecise (fuzzy) in nature due to the expert's ambiguous understanding of their nature.

To overcome the above difficulties, fuzzy programming (FP) approach [4] as well as fuzzy goal programming (FGP) [5] approach to crops production planning has been studied $[6,7]$ in the past.

Now, in most of the real-world decision situations, the DMs are often faced with the problem of inexact data due to inherent uncertain in nature of the resource parameters involved with the problems. To deal with the probabilistically uncertain data, the field of stochastic programming (SP) has been studied [8] extensively and applied to various real-life problems [9] in the past.

However, consideration of both the aspects of FP and SP for modeling and solving real-life decision problems has been realized in the recent years from the view point of occurrence of both the fuzzy and probabilistic data in the decision making environment.

Although, fuzzy stochastic programming (FSP) approaches to chance constrained MODM problems have been investigated [10] by active researchers in the field, the extensive study in this area is at an early stage. 
Now, in the agricultural production planning context, it is worthy to mention that the sustainable supply of water depends solely on the amount of rainfall in all the seasons throughout a year. As such, water supply to meet various needs is very much stochastic in nature.

Now, it is to be observed that non-linearity in fractional form appears in most of the farm planning decision situations due to consideration of different ratios involved with the problems.

The fractional programming as a special field of non-linear programming has been studied [11] extensively in the past for both the single objective and multiobejctive programming problems. The linearization approach to FP as well as FGP problems with linear fractional criteria have been studied [12] in the past.

Now, it is worthy to mention here that there are several socioeconomic objectives to be satisfied in modelling and solving farm planning problems, which are often incommensurable in nature and they are inherently nonlinear in form in a decision making horizon. Here, the traditional approximation method is generally used to solve nonlinear multiobjective decision making (MODM) problems [13]. But computational load is involved there and local optimal solutions are often achieved in an actual practice.

To overcome the computational difficulties arising out of using traditional (single-point based) solution search approaches, GAs based on the natural selection and population genetics, initially introduced by Holland [14] have appeared as volume-oriented global solution search tools to solve complex real-world problems. The extensive study on the use of GAs as goal satisficers rather than objective optimisers to multiobjective decision problems in crisp decision environment has been discussed by Deb [15]. But, exploration of the potential use of GAs to MODM problems is yet to be circulated in the literature.

This article presents how the priority based FGP method can be efficiently used for modelling and solving agricultural planning problems for achieving the aspiration levels of production of various seasonal crops cultivated by allocating the arable land properly and utilizing the available productive resources efficiently throughout the planning year. In the proposed approach, utilization of total cultivable land, different farming resources, achievement of the aspiration levels of production of seasonal crops are fuzzily described.

The data of the planning year 2005-2006 are collected from different agricultural planning units. The sources are: District Statistical Hand Book, Nadia, 2005-2006 [16]; Action Plan Records (2005-2006 and 2004-2005) [17]; Soil Testing and Fertilizer Recommendation [18]; The Nadia Gramin Bank; Department of Agri-Irrigation [19]. Now, the three seasonal crop-cycles: Pre-kharif, Kharif and Rabi successively appear in West Bengal during a planning year, and they are used to designate the time periods for crops production during summer, rainy and winter seasons, respectively, in a year.

In the model formulation of the problem, the concept of tolerance membership functions in fuzzy sets for measuring the degree of optimality of crops production by utilizing the productive resources is considered.

In the solution process, an GA scheme as a global solution search approach is employed to the FGP formulation of the proposed problem to evaluate the goal achievement functions defined for achieving the highest membership value (unity) of the fuzzy goals of the model to the extent possible on the basis of priorities assigned to them and thereby to reach a most satisfactory solution in the decision making situation. The potential use of the approach is demonstrated by a case example of the Nadia District, West Bengal (W. B.), INDIA. Now, the general chance constrained FGP formulation is presented in the Section 2.

\section{CHANCE CONSTRAINED FGP FORMULATION}

The generic form of chance constrained FP problem can be presented as:

Find $\mathrm{X}\left(\mathrm{x}_{1}, \mathrm{x}_{2}, \ldots, \mathrm{x}_{\mathrm{n}}\right)$ so as to

$$
\mathrm{Z}_{\mathrm{k}}(\mathrm{X})\left(\begin{array}{l}
\gtrsim \\
\lesssim
\end{array}\right) \mathrm{g}_{\mathrm{k}}, \quad \mathrm{k}=1,2, \ldots, \mathrm{K} .
$$

subject to

$$
x \in S\left\{x \in R^{n} \mid \operatorname{Pr}[A(X) \geq b] \geq p, \mathrm{x} \geq 0, \mathrm{~b} \in \mathrm{R}^{\mathrm{m}}\right\},
$$

where $\mathrm{X}$ is the vector of decision variables, and where $\&$ and indicate the fuzziness of $\geq$ and $\leq$ restrictions, respectively, in the sense of Zimmermann [20], and where gk be the imprecise aspiration level of the k-th objective $\mathrm{Fk}(\mathrm{X}),(\mathrm{k}=$ $1,2, \ldots ., \mathrm{K})$, Pr stands for probabilistically defined constraints, $\mathrm{F}($.$) is a function (linear or non-linear) of constrained$ coefficients set , $b$ is a resource vector, and $p(0<p<1)$ is the vector of satisficing probability levels defined for the randomized constraints set.

Now, in the field of FP, the fuzzy goals are characterized by their respective membership functions.

\subsection{Characterization of Membership Function}

Let $\mathrm{t}_{\ell \mathrm{k}}$ and $\mathrm{t}_{\mathrm{uk}}$ be the lower- and upper-tolerance ranges, respectively, for achievement of the aspired level $b_{k}$ of the kth fuzzy goal. Then, the membership functions, say $\mu_{\mathrm{k}}(\mathrm{X})$, for the fuzzy goal $\mathrm{F}_{\mathrm{k}}(\mathrm{X})$ can be characterized as follows [12]. For $\gtrsim$ type of restriction, $\mu_{\mathrm{k}}(\mathrm{X})$ takes the form

$\mu_{k}(X)=\left\{\begin{array}{cl}1 & , \text { if } F_{k}(x) \geq g_{k} \\ \mathrm{~F}_{k}(x)-\left(g_{k}-t_{f k}\right) & , \text { if } g_{k}-t_{f k} \leq F_{k}(x)<g_{k} \\ t_{f k} & , \text { if } F_{k}(x)<g_{k}-t_{f k}\end{array}\right.$

where $\left(\mathrm{g}_{\mathrm{k}}-t_{\ell k}\right)$ represents the lower-tolerance limit for achievement of the stated fuzzy goal.

Again, for $\lesssim$ type of restriction, $\mu_{\mathrm{k}}(\mathrm{X})$ becomes

$\mu_{k}(X)=\left\{\begin{array}{cl}1 & , \text { if } F_{k}(x) \leq g_{k} \\ \frac{\left(g_{k}+t_{u k}\right)-F_{k}(X)}{t_{u k}} & , \text { if } g_{k}<F_{k}(x) \leq g_{k}+t_{u k} \\ 0 & \text { if } F_{k}(x)>g_{k}+t_{u k}\end{array}\right.$

where $\left(\mathrm{g}_{\mathrm{k}}+\mathrm{t}_{\mathrm{uk}}\right)$ represents the upper-tolerance limit for achievement of the stated fuzzy goal.

Now, in the chance constrained decision making context, the widely used approach to decision problems is the conversion of the chance constraints to their deterministic equivalent [10]. 


\subsection{Deterministic equivalent of Chance Constraints}

The deterministic equivalent of a chance constraint depends on the probability distribution followed by the random parameters involved with the constraint. In the present decision situation, the independent normally distributed random parameters are taken into consideration.

\subsubsection{Linear Chance Constraints}

The chance constraints in (2) in linear form can be explicitly presented as:

$\operatorname{Pr}\left[\sum_{\mathrm{j}=1}^{\mathrm{n}} \mathrm{a}_{\mathrm{ij}} \mathrm{x}_{\mathrm{j}} \geq \mathrm{b}_{\mathrm{i}}\right] \geq \mathrm{p}_{\mathrm{i}}, \mathrm{i}=1,2, \ldots, \mathrm{m}_{1}, \quad \mathrm{~m}_{1}<\mathrm{m}$

where, $a_{i j}$ and $b_{i}\left(i=1,2, \ldots, m_{1} ; j=1,2, \ldots, n\right)$ are the random coefficients and resource vector elements, respectively, and $p_{i}$ is the $\mathrm{i}$-th satisficing level of probability.

Then, using the standard probability rules, the deterministic equivalent of the expressions in (5) in quadratic form appear as

$\left.\mathrm{E}\left(\mathrm{y}_{\mathrm{i}}\right)+\mathrm{F}_{\mathrm{i}}^{-1}\left(1-\mathrm{p}_{\mathrm{i}}\right) \sqrt{\left\{\operatorname{var}\left(\mathrm{y}_{\mathrm{i}}\right)\right.}\right\} \geq 0, \mathrm{i} \in \mathrm{m}_{1}$

where $\mathrm{y}_{\mathrm{i}}=\left(\sum_{\mathrm{j}=1}^{\mathrm{n}} \mathrm{a}_{\mathrm{ij}} \mathrm{x}_{\mathrm{j}}-\mathrm{b}_{\mathrm{i}}\right), \mathrm{F}^{-1}($.) represents the inverse of the probability distribution function $\mathrm{F}($.$) , and where \mathrm{E}\left(\mathrm{y}_{\mathrm{i}}\right)$ and $\operatorname{var}\left(\mathrm{y}_{\mathrm{i}}\right)$ designate the mean and variance.

\subsubsection{Fractional Chance Constraints}

The fractional form of the chance constraints can be represented as:

$\operatorname{Pr}\left[\frac{f_{i}(X)}{h_{i}(X)} \geq b_{i}\right] \geq p_{i}, \quad i=m_{1}+1, m_{1}+2, \ldots, m$

where $\mathrm{f}_{\mathrm{i}}(\mathrm{X})$ and $\mathrm{hi}(\mathrm{X})$ are linear in form, and bi, is a random variable.

Then, the linear fractional equivalent of the expressions in (7) takes the form:

$$
\left.\frac{\mathrm{f}_{\mathrm{i}}(\mathrm{X})}{\mathrm{h}_{\mathrm{i}}(\mathrm{X})} \geq \mathrm{E}\left(\mathrm{b}_{\mathrm{i}}\right)+\mathrm{F}_{\mathrm{i}}^{-1}\left(\mathrm{p}_{\mathrm{i}}\right) \sqrt{\left\{\operatorname{var}\left(\mathrm{b}_{\mathrm{i}}\right)\right.}\right\}
$$

where, $E\left(b_{i}\right)$ and $\operatorname{var}\left(b_{i}\right)$ represent mean and variance of $b_{i}$. Now, the general FGP model formulation of the problem is presented in the following Section 2.3.

\subsection{FGP Model Formulation}

In the FGP model formulation, the membership functions in (3) and (4) are transformed into flexible membership goals by assigning highest membership value (unity) as the aspiration levels and introducing under- and over-deviational variables to each of them.

Then, the FGP model under a pre-emptive priority structure can be presented as

Find $\mathrm{X}\left(\mathrm{x}_{1}, \mathrm{x}_{2}, \ldots, \mathrm{x}_{\mathrm{n}}\right)$ so as to

Minimize $\mathrm{Z}=\left[\mathrm{P}_{1}\left(d^{-}\right), \mathrm{P}_{2}\left(d^{-}\right), \ldots, \mathrm{P}_{\mathrm{r}}\left(d^{-}\right), \ldots, \mathrm{P}_{\mathrm{R}}\left(d^{-}\right)\right]$

and satisfy

$$
\begin{aligned}
& \frac{F_{k}(\mathbf{X})-\left(g_{k}-t_{\ell k}\right)}{t_{\ell k}}+d_{k}^{-}-d_{k}^{+}=1 \\
& \frac{\left(g_{k}+t_{u k}\right)-F_{k}(\mathbf{X})}{t_{u k}}+d_{k}^{-}-d_{k}^{+}=1
\end{aligned}
$$

subject to the system constraints sets in (6) and (8), where $\mathrm{d}_{\mathrm{k}}^{-}, \mathrm{d}_{\mathrm{k}}^{+} \geq 0, \mathrm{k}=1,2, \ldots, \mathrm{K}$, are the under- and overdeviational variables of the $\mathrm{k}$-th goal, and where $\mathrm{Z}$ represents the vector of $R$ priority achievement function. $\mathrm{P}_{\mathrm{r}}\left(\mathrm{d}^{-}\right)$is a linear function of the weighted under-deviational variables, where $\mathrm{P}_{\mathrm{r}}\left(\mathrm{d}^{-}\right)$is of the form

$\mathrm{P}_{\mathrm{r}}\left(\mathrm{d}^{-}\right)=\sum_{\mathrm{k}=1}^{\mathrm{K}} \mathrm{W}_{\mathrm{rk}}^{-} d_{\mathrm{rk}}^{-} \quad, \quad \mathrm{k}=1,2, \ldots, \mathrm{K} ;(\mathrm{R} \leq \mathrm{K})$,

where $\mathrm{d}_{\mathrm{rk}}^{-}$is renamed for $\mathrm{d}_{\mathrm{k}}^{-}$to represent it at the $\mathrm{r}$-th priority level, $\mathrm{w}_{\mathrm{rk}}^{-}(>0)$ is the numerical weight associated with $\mathrm{d}_{\mathrm{rk}}^{-}$and it designates the weight of importance of achieving the aspired level of the k-th goal relative to other which are grouped at the $\mathrm{r}$-th priority level and where $\mathrm{w}_{\mathrm{rk}}$ values are determined as [12] :

$w_{r k}^{-}=\left\{\begin{array}{l}\frac{1}{\left(t_{\ell k}\right)_{r}}, \text { for the defined } \mu_{\mathrm{k}}(\mathbf{X}) \text { in (3) } \\ \frac{1}{\left(t_{\ell k}\right)_{r}}, \text { for the defined } \mu_{\mathrm{k}}(\mathbf{X}) \text { in (4) }\end{array}\right.$

where $\left(\mathrm{t}_{\ell \mathrm{k}}\right)_{\mathrm{r}}$ and $\left(\mathrm{t}_{\mathrm{uk}}\right)_{\mathrm{r}}$ are used to present $t_{\ell k}$ and $t_{u k}$, respectively, at the $\mathrm{r}$-th priority level.

\section{DESIGN OF GA SCHEME}

In the literature of GAs, there is a variety of schemes [10,21] for generating new population with the use of different operators: selection, crossover and mutation. In the present GA scheme, real-valued representation of candidate solutions is considered in the evaluation process of the problem. The tournament selection scheme in [14], arithmetic crossover [15] and uniform mutation operations are adopted to generate offspring in new population in search domain defined in the decision making environment.

Now, the FGP model formulation of the problem is presented in the Section 4.

\section{FGP MODEL FORMULATION}

The decision variables and different types of parameters involved with the problem are defined first in the following Section 4.1.

\subsection{Definition of Decision Variables and Parameters}

\subsubsection{Decision Variable}

$l_{c s}=$ Allocation of land for cultivating the crop $c$ during the season $s, c=1,2, \ldots, C ; s=1,2, \ldots, S$.

\subsubsection{Productive Resource Parameters}

- Fuzzy resources:

$L A_{s} \quad=$ Total farming land (hectares (ha)) currently in use for cultivating the crops in the season $s$.

$M H_{s}=$ Estimated total machine hours (in hrs.) required during the season $s$.

$M D_{s}=$ Estimated total man-days (in days) required during the season $s$.

$F_{f}=$ Estimated total amount of the fertilizer $f(f=1,2, \ldots, F)$ (in quintals (qtls.)) required during the planning year.

$R S=$ Estimated total amount of cash (in Rupees (in Rs.)) required per annum for supply of the productive resources.

- Probabilistic resource:

$W S_{s}=$ Total supply of water (in inch / ha) required during the 
season $s$.

\subsubsection{Fuzzy Aspiration Levels}

$P_{c}=$ Annual production level (in qtls.) of the crop $c$.

$M P=$ Estimated total market value (in Rs.) of all the crops yield during the planning year.

\subsubsection{Probabilistic Aspiration Levels}

$R_{i j}=$ Ratio of annual production of the $i$-th and $j$-th crop

$$
(i, j=1,2, \ldots, C ; i \neq j) \text {. }
$$

$r_{i j}=$ Ratio of annual profits obtained from the $i$-th and the

$j$-th crops $(i, j=1,2, \ldots, C ; i \neq j)$

\subsubsection{Crisp Coefficients}

$M H_{c s}=$ Average machine hours (in hrs.) required for tillage per ha of land for cultivating the crop $c$ during the season $s$.

$M D_{c s}=$ Man days (in days) required per ha of land for cultivating the crop $c$ during the season $s$.

$F_{f c s}=$ Amount of the fertilizer $f$ required per ha of land for cultivating the crop $c$ during the season $s$.

$P_{c s}=$ Estimated production of the crop $c$ per ha of land cultivated during the season $s$.

$A_{c s}=$ Average cost for purchasing seeds and different farm assisting materials per ha of land cultivated for the crop $c$ during the season $s$.

$M P_{c s}=$ Market price (Rs. / qtl.) at the time of harvest of the crop $c$ cultivated during the season $s$.

\subsubsection{Random Coefficients}

$W_{c s}=$ Estimated amount of water consumption (in inch) per ha of land for cultivating the crop $c$ during the season $s$

\subsection{Description of Fuzzy Goals and Chance Constraints}

\subsubsection{Land Utilization Goal.}

The land utilization goal for cultivating the seasonal crops appears as:

$$
\sum_{c=1}^{C} l_{c s} \lesssim L A_{s}, \quad s=1,2, \ldots, S .
$$

\subsubsection{Productive Resource Goals}

- Machine-hour goal: An estimated number of machine hours is to be provided for cultivating the land in different seasons of the plan period.

The fuzzy goals take the form:

$$
\sum_{c=1}^{C} M H_{c s} . l_{\mathrm{cs}} \gtrsim M H_{S}, \quad s=1,2, \ldots, S .
$$

- Man-power requirement goals: A number of labourers are to be employed through out the planning period to avoid the trouble with hiring of extra labourers at the peak times.

The fuzzy goals take the form:

$$
\sum_{c=1}^{C} M D_{c s} . l_{c s} \gtrsim M D_{s} . \quad s=1,2, \ldots, S .
$$

- Fertilizer requirement goals: To maintain the fertility of the soil, different types of fertilizer are to be used in different seasons in the plan period.

The fuzzy goals take the form:

$$
\sum_{c=1}^{C} F_{f c s} \cdot l_{c s} \gtrsim F_{f}, \quad f=1,2, \ldots, F ; s=1,2, \ldots, S .
$$

\subsubsection{Cash Expenditure Goals}

An estimated amount of money (in Rs.) is involved for the purpose of purchasing the seeds, fertilizers and other productive resources.

The fuzzy goals take the form:

$$
\sum_{S=1}^{S} \sum_{c=1}^{C} A_{c s} \cdot l_{c s} \gtrsim R S
$$

\subsubsection{Production Achievement Goals}

To meet the demand of agricultural products in society, a minimum achievement level of production of each type of the crops is needed.

The fuzzy goals appear as:

$$
\sum_{s=1}^{S} P_{c s} . l_{c s} \gtrsim P_{c}, \quad c=1,2, \ldots, C .
$$

\subsubsection{Profit Goals}

A certain level of profit from the farm is highly expected by the farm decision maker.

$$
\begin{gathered}
\text { The fuzzy profit goal appears as: } \\
\sum_{s=1}^{S} \sum_{c=1}^{C}\left(M P_{c s} \cdot P_{c s}-A_{c s}\right) \cdot l_{\mathrm{cs}} \gtrsim M P
\end{gathered}
$$

\subsection{Description of Chance Constraints}

The different chance constraints of the problem are presented in the following Sections.

\subsubsection{Water-Supply Constraints}

An estimated amount of water need be supplied to the soil for sustainable growth of the crop $c$ cultivated during the season $s$. But, water-supply resources solely depends on rainfall and so probabilistic in nature.

The water-supply constraints appear as

$$
\operatorname{Pr}\left[\sum_{c=1}^{C} W_{c s} l_{c s} \geq W S_{s}\right] \geq p_{s}, s=1,2, \ldots, S .
$$

where $p_{s}\left(0<p_{s}<1\right)$ denotes the satisficing level of probability for the supply of water.

\subsubsection{Production-Ratio Constraints}

To meet the demand of the primary food products in society, allocation of land for the crops production in different seasons should be made in such a way that certain ratios of total production of major crops can be maintained.

The production-ratio constraints appear as:

$$
\operatorname{Pr}\left[\frac{\sum_{s=1}^{S} P_{i s} l_{i s}}{\sum_{s=1}^{S} P_{j s} l_{j s}} \geq R_{i j}\right] \geq p_{i j}, \quad i, j=1,2, \ldots, C \text {, and } i \neq j .
$$

where $p_{i j}\left(0<p_{i j}<1\right)$ denotes the satisficing level of probability for the ratios of $i$-th and $j$-th crops.

\subsubsection{Profit-Ratio Constraints}

Here, similar to the case in production-ratio constraints, the profit-ratio constraints are random in nature. The profit-ratio constraints take the form: 
$\operatorname{Pr}\left[\frac{\left(\sum_{s=1}^{S}\left(M P_{i s} \cdot P_{i s}-A_{c s}\right) l_{i s}\right)}{\left(\sum_{s=1}^{S}\left(M P_{j s} \cdot P_{j s}-A_{c s}\right) l_{j s}\right)} \geq r_{i j}\right] \geq q_{i j}, \quad i, j=1,2, \ldots, C$, and $i \neq j$.

where, $q_{i j}\left(0<q_{i j}<1\right)$ denotes the satisficing level of probability for the $i$-th and $j$-th profit-ratio.

\section{AN ILLUSTRATIVE CASE EXAMPLE:} A CASE STUDY

The land-use planning problem for production of the principal crops of the District Nadia of West Bengal, India is considered to illustrate the FGP model. The data of the planning years: 2003-2004, 2004-2005 and 2005-2006 were collected from different agricultural planning units. Now, the three seasonal crop-cycles: Pre-kharif, Kharif and Rabi successively appear in W.B. during a planning year, and they designate the time periods for crop production during summer, rainy and winter seasons, respectively. The data were collected from different sources such as Statistical Hand Book, Nadia, 2005-2006 [16]; Action Plan Records (20052006 and 2004-2005) [17]; Soil Testing and Fertilizer Recommendation [18]; The Nadia Gramin Bank; Department of Agri-Irrigation [19].

Now, the decision variables and different types of model data are summarized in the Tables 1-4.

Table 1. Summary of the Seasonal Crops and Decision Variables

\begin{tabular}{|l|l|l|l|l|l|l|l|l|l|}
\hline $\begin{array}{l}\text { Season } \\
(s)\end{array}$ & \multicolumn{2}{|l|}{ Pre-kharif $(1)$} & $\begin{array}{l}\text { Kharif } \\
(2)\end{array}$ & \multicolumn{5}{|c|}{ Rabi (3) } \\
\hline $\begin{array}{l}\text { Crop } \\
(c)\end{array}$ & $\begin{array}{l}\text { Jute } \\
(1)\end{array}$ & $\begin{array}{l}\text { Sugar } \\
\text { cane } \\
(2)\end{array}$ & $\begin{array}{l}\text { Aus- } \\
\text { paddy } \\
(3)\end{array}$ & $\begin{array}{l}\text { Aman- } \\
\text { paddy } \\
(4)\end{array}$ & $\begin{array}{l}\text { Boro- } \\
\text { paddy } \\
(5)\end{array}$ & $\begin{array}{l}\text { Wheat } \\
(6)\end{array}$ & $\begin{array}{l}\text { Mustard } \\
(7)\end{array}$ & $\begin{array}{l}\text { Potato } \\
(8)\end{array}$ & $\begin{array}{l}\text { Pulses } \\
(9)\end{array}$ \\
\hline $\begin{array}{l}\text { Variable } \\
\left(l_{c s}\right)\end{array}$ & $l_{11}$ & $l_{21}$ & $l_{31}$ & $l_{42}$ & $l_{53}$ & $l_{63}$ & $l_{73}$ & $l_{83}$ & $l_{93}$ \\
\hline
\end{tabular}

Table 2. Summary of the Seasonal Crops and Decision Variables

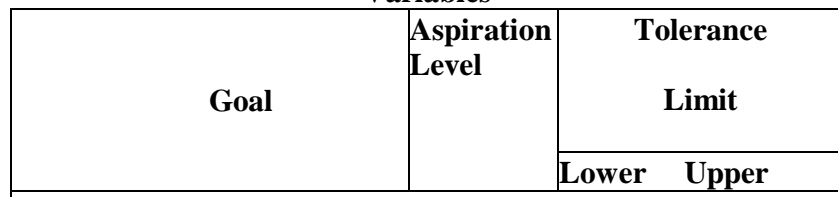

1. Land utilization ('000

hectares) :

\begin{tabular}{|c|c|c|}
\hline (i) Pre-kharif season & 272.14 & ---- \\
\hline (ii) Kharif season & 272.14 & ---- \\
\hline (iii) Rabi season & 272.14 & \\
\hline 2. a) Machine-hours (in hrs.) : & & \\
\hline (i) Pre-kharif season & 1189.42 & $\begin{array}{l}1103.6 \\
9\end{array}$ \\
\hline (ii) Kharif season & 602.88 & 563.07 \\
\hline (iii) Rabi season & 2896.68 & $\begin{array}{c}2822.7 \\
9\end{array}$ \\
\hline $\begin{array}{l}\text { b) Man-days (days) : } \\
\text { (i) Pre-kharif season }\end{array}$ & 345.28 & 340.37 \\
\hline i) Kharif season & 177.32 & 165.61 \\
\hline $\begin{array}{l}\text { ii) Rabi season } \\
\text { Fertilizer requirement }\end{array}$ & 379.35 & 363.04 \\
\hline
\end{tabular}

\begin{tabular}{|c|c|c|c|}
\hline \multirow[t]{2}{*}{ Goal } & \multirow[t]{2}{*}{\begin{tabular}{|l|} 
Aspiration \\
Level
\end{tabular}} & \multicolumn{2}{|c|}{$\begin{array}{c}\text { Tolerance } \\
\text { Limit }\end{array}$} \\
\hline & & Lower & Upper \\
\hline (metric ton) : & & & \\
\hline (i) Nitrogen & 34.97 & 34.70 & ---- \\
\hline (ii) Phosphate & 19.62 & 18.80 & --- \\
\hline (iii) Potash & 16.72 & 15.20 & ---- \\
\hline $\begin{array}{l}\text { 3. Production ('000 metric } \\
\text { ton): }\end{array}$ & & & \\
\hline (a) Jute & 325.15 & 308.68 & ---- \\
\hline (b) Sugarcane & 139.00 & 118.00 & ---- \\
\hline (c) Rice & 800.00 & 732.32 & ---- \\
\hline (d) Wheat & 111.78 & 100.40 & ---- \\
\hline (e) Mustard & 78.50 & 71.40 & ---- \\
\hline (f) Potato & 147.50 & 111.77 & --- \\
\hline (g) Rabi pulse & 42.46 & 38.60 & ---- \\
\hline $\begin{array}{l}\text { 4. Cash expenditure (Rs. } \\
\text { Lack.) }\end{array}$ & 83965.32 & --- & 92361.32 \\
\hline 5. Profit (Rs. Lack.) & 93849.42 & $\begin{array}{l}84141 . \\
50\end{array}$ & ----- \\
\hline
\end{tabular}

Table 3. Data Description of Productive Resource

Utilization, Cash Expenditure and Market Price

\begin{tabular}{|c|c|c|c|c|c|c|c|c|}
\hline \multirow{2}{*}{ Crops } & \multirow{2}{*}{$M_{S}$} & \multirow{2}{*}{$M D_{s}$} & \multicolumn{3}{|c|}{$\boldsymbol{F}_{f}$} & \multirow{2}{*}{$P A$} & \multirow{2}{*}{$C E$} & \multirow{2}{*}{$M P$} \\
\hline & & & $N$ & $P$ & $K$ & & & \\
\hline Jute & 204 & 90 & 40 & 20 & 20 & 2693.27 & 17297.00 & 1600 \\
\hline Sugarcane & 510 & 123 & 200 & 100 & 100 & 78666.60 & 30887.50 & 1300 \\
\hline Aus & 425 & 60 & 40 & 20 & 20 & 2203.46 & 14331.80 & 1100 \\
\hline Aman & 204 & 60 & 40 & 20 & 20 & 2513.88 & 12849.20 & 1300 \\
\hline Boro & 816 & 60 & 100 & 50 & 50 & 3253.95 & 23721.60 & 1000 \\
\hline Wheat & 204 & 39 & 100 & 50 & 50 & 2131.63 & 11119.50 & 900 \\
\hline Mustard & 102 & 30 & 80 & 40 & 40 & 901.52 & 8401.40 & 1500 \\
\hline Potato & 340 & 70 & 150 & 75 & 75 & 26818.18 & 37312.10 & 430 \\
\hline Pulses & 150 & 15 & 20 & 50 & 20 & 831.89 & 4942.00 & 1700 \\
\hline
\end{tabular}

Note: $\mathrm{MH}_{\mathrm{s}}=$ machine hours (in hrs/ha), $\mathrm{MD}_{\mathrm{s}}=$ man-days (days/ha), $\mathrm{F}_{\mathrm{f}}=$ fertilizer $(\mathrm{kg} / \mathrm{ha})$ : $\mathrm{N}=$ Nitrogen, $\mathrm{P}=$ Phosphate, $\mathrm{K}=$ Potash $\mathrm{PA}=$ production achievement $(\mathrm{kg} / \mathrm{ha}), \mathrm{CE}=\mathrm{cash}$ expenditure $(\mathrm{Rs} / \mathrm{ha}), \mathrm{MP}=$ market price $(\mathrm{Rs} / \mathrm{qtl})$.

Table 4. Data Description of Water-Supply, WaterUtilization, Production-Ratio and Profit-Ratio

\begin{tabular}{|c|ccc|}
\hline \multirow{2}{*}{$\begin{array}{c}\text { WU } \\
\text { i })\end{array}$} & \multicolumn{3}{|c|}{ Year } \\
& $\downarrow$ & \multicolumn{3}{|c|}{} \\
\cline { 2 - 4 } & $2003-2004$ & $2004-2005$ & $2005-2006$ \\
\hline 1 & 20 & 20 & 20 \\
2 & 60 & 60 & 60 \\
3 & 34 & 34 & 34 \\
4 & 50 & 50 & 50
\end{tabular}




\begin{tabular}{|c|c|c|c|}
\hline 5 & 70 & 70 & 70 \\
\hline 6 & 15 & 15 & 15 \\
\hline 7 & 10 & 10 & 10 \\
\hline 8 & 18 & 18 & 18 \\
\hline 9 & 10 & 10 & 10 \\
\hline$W S(P K S, K S, R S)$ & $\begin{array}{c}\text { (116.93, } \\
159.85, \\
264.62)\end{array}$ & $\begin{array}{c}(119.42, \\
147.76, \\
335.92)\end{array}$ & $\begin{array}{l}(100.44, \\
147.77, \\
243.49)\end{array}$ \\
\hline $\begin{array}{c}\text { PDR (Rice and } \\
\text { Wheat })\end{array}$ & 6.22 & 7.39 & 6 \\
\hline $\begin{array}{c}\text { PR(Jute and } \\
\text { Aus-paddy) }\end{array}$ & 1.17 & 2.27 & 5.5 \\
\hline
\end{tabular}

Note: $W U(i)=$ Water-utilization $($ inch/ha) for the i-th crop $(\mathrm{i}=1,2, \ldots, 9), W S()=$. Water-supply (inch): $P K S=$ Pre-kharif season, $K S=$ Kharif season, $R S=$ Rabi season, $\mathrm{PDR}=$ Production-ratio, $P R=$ Profit-ratio

Now, using the data Tables 1-3, the membership functions of the defined fuzzy goals can be constructed by using the expressions in (3) and (4).

The fuzzy goals appear as follows:

\subsection{Land Utilization Goals}

The membership goals for land utilization in the three consecutive seasons appear as

$$
\begin{gathered}
\mu_{1}: 8.32-0.027\left(l_{11}+l_{21}+l_{31}\right)+d_{1}^{-}-d_{1}^{+}=1 \\
\text { (Pre-kharif) } \\
\mu_{2}: 8.32-0.027\left(l_{21}+l_{42}\right)+d_{2}^{-}-d_{2}^{+}=1
\end{gathered}
$$

$$
\mu_{3}: 8.32-0.027\left(l_{21}+l_{53}+l_{63}+l_{73}+l_{83}+l_{93}\right)+d_{3}^{-}-d_{3}^{+}=1
$$

\subsection{Productive Resource}

\subsubsection{Machine-hour Goal}

$$
\begin{aligned}
& \mu_{4}: 0.06 l_{11}+0.16 l_{21}+0.13 l_{31}-13.97+\mathrm{d}_{4}^{-}-\mathrm{d}_{4}^{+}=1 \\
& \text { (Prekharif) } \\
& \mu_{5}: 1.27 l_{42}-14.14+\mathrm{d}_{5}^{-}-\mathrm{d}_{5}^{+}=1 \\
& \mu_{6}: 0.27 l_{53}+0.07 l_{63}+0.03 l_{73}+0.11 l_{83} \\
& \quad+0.05 l_{93}+13.97+\mathrm{d}_{6}^{-}-\mathrm{d}_{6}^{+}=1 \quad \text { (Kharif) }
\end{aligned}
$$

\subsubsection{Man-power goal}

$$
\begin{aligned}
& \mu_{7}: 0.45 l_{11}+0.62 l_{21}+0.30 l_{31}-69.33+d_{7}^{-}-d_{7}^{+}=1 \\
& \begin{array}{l}
\text { (Prekharif) } \\
\mu_{8}: 0.13 l_{42}-14.14+d_{8}^{-}-d_{8}^{+}=1
\end{array} \\
& \mu_{9}: 0.09 l_{53}+0.06 l_{63}+0.11 l_{73}+0.05 l_{83} \text { (Kharif) } \\
& \quad+0.02 l_{93}-22.25+d_{9}^{-}-d_{9}^{+}=1
\end{aligned}
$$

\subsubsection{Fertilizer requirement goals}

$$
\begin{aligned}
\mu_{10} & : 0.15 l_{11}+0.73 l_{21}+0.15 l_{31}+0.15 l_{42} \\
& +0.04 l_{53}+0.04 l_{63}+0.29 l_{73}+0.55 l_{83} \\
& +0.07 l_{93}-127.11+d_{10}^{-}-d_{10}^{+}=1
\end{aligned}
$$

$$
\begin{aligned}
\mu_{11}: & 0.02 l_{11}+0.01 l_{21}+0.02 l_{31}+0.02 l_{42} \\
& +0.06 l_{53}+0.06 l_{63}+0.05 l_{73}+0.15 l_{83} \\
& +0.06 l_{93}-22.99+d_{11}^{-}-d_{11}^{+}=1 \\
\mu_{12}: & 0.01 l_{11}+0.03 l_{21}+0.01 l_{31}+0.01 l_{42} \\
& +0.01 l_{53}+0.01 l_{63}+0.01 l_{73}+0.03 l_{83} \\
& +0.01 l_{93}-4.28+d_{12}^{-}-d_{12}^{+}=1
\end{aligned}
$$

\subsection{Cash Expenditure Goal}

$$
\begin{aligned}
\mu_{13} & : 10.99-\left(0.02 l_{11}+0.04 l_{21}+0.02 l_{31}\right. \\
& +0.02 l_{42}+0.03 l_{53}+0.01 l_{63}+0.04 l_{73} \\
& \left.+0.01 l_{83}+0.01 l_{93}\right)+d_{13}^{-}-d_{13}^{+}=1
\end{aligned}
$$

\subsection{Production Achievement Goals}

$\begin{array}{lc}\mu_{14}: 0.03 l_{31}+0.04 l_{42}+0.05 l_{53}-10.83+d_{14}^{-}-d_{14}^{+}=1 \text { (Rice) } \\ \mu_{15}: 0.16 l_{11}-18.74+d_{15}^{-}-d_{15}^{+}=1 & \text { (Jute) } \\ \mu_{16}: 0.19 l_{63}-8.82+d_{16}^{-}-d_{16}^{+}=1 & \text { (Wheat) } \\ \mu_{17}: 3.93 l_{21}-5.9+d_{17}^{-}-d_{17}^{+}=1 & \text { (Sugercane) } \\ \mu_{18}: .1269 l_{73}-10.06+d_{18}^{-}-d_{18}^{+}=1 & \text { (Mustard) } \\ \mu_{19}: 0.75 l_{83}-3.13+d_{19}^{-}-d_{19}^{+}=1 & \text { (Poteto) } \\ \mu_{20}: 0.22 l_{93}-9.99+d_{20}^{-}-d_{20}^{+}=1 & \text { (Pulses) }\end{array}$

\subsection{Profit Achievement Goal}

$$
\begin{aligned}
\mu_{21} & : 0.0278 l_{11}+0.1037 l_{21}+0.0106 l_{31}+0.0212 l_{42} \\
& +0.0198 l_{53}+0.0086 l_{63}+0.0055 l_{73}+0.0834 l_{83} \\
& +0.0098 l_{93}-8.9947+d_{21}^{-}-d_{21}^{+}=1
\end{aligned}
$$

Now, using the data in the Table 4 and following the procedure, the deterministic equivalent of the defined chance constraints can be obtained by using the expression (6) and (8).

\subsection{Water-Supply Constraints}

$$
\begin{aligned}
& 2.471\left(20 l_{11}+60 l_{21}+34 l_{31}\right) \geq 10958.73 \\
& 2.471\left(50 l_{42}\right) \geq 14743.99 \\
& 2.471\left(70 l_{53}+15 l_{63}+10 l_{73}+18 l_{83}+10 l_{93}\right) \geq 21926.45
\end{aligned}
$$

\subsection{Production-Ratio Constraint}

The ratio of the two crops rice and wheat are considered here as the major agricultural products.

The production ratio constraint appears as:

$$
\frac{2.187 l_{31}+2.285 l_{42}+3.336 l_{53}}{1.882 l_{63}} \geq 8.044
$$

\subsection{Profit-Ratio Constraint}

The profit ratio for Jute and Aus-paddy in the pre-kharif season is taken into account here.

The profit-ratio constraint takes the form:

$$
\frac{259.84 l_{11}}{99.06 l_{21}+969.45 l_{31}} \geq 3.75
$$

Now, the executable FGP model under the four assigned priorities appears as:

Find $\left\{l_{c s} \mid c=1,2, \ldots, 9 ; s=1,2,3\right\}$ so as to: 
Minimize

$\mathrm{Z}=\left[\mathrm{P}_{1}\left(0.014 d_{14}^{-}+0.06 d_{15}^{-}+0.088 d_{16}^{-}+0.048 d_{17}^{-}+0.14 d_{18}^{-}+\right.\right.$ $\left.0.028 d_{19}^{-}+0.26 d_{20}^{-}\right)$,

$\mathrm{P}_{2}\left(0.027 d_{1}^{-}+0.027 d_{2}^{-}+0.027 d_{3}^{-}\right), \mathrm{P}_{3}\left(0.012 d_{4}^{-}+0.025 d_{5}^{-}+\right.$ $0.014 d_{6}^{-}+0.2 d_{7}^{-}+0.09 d_{8}^{-}+0.06 d_{9}^{-}$

$\left.\left.+3.7 d_{10}^{-}+1.2 d_{11}^{-}+0.65 d_{12}^{-}\right), \quad \mathrm{P}_{4}\left(0.00012 d_{13}^{-}+0.0001 d_{21}^{-}\right)\right]$

and satisfy the membership goals in (11)-(17), subject to the systen constraints in $(18)-(20)$.

Now, employing the GA scheme, the achievement function $Z$ in (21) appears the fitness function as defined in (10) in the process of solving the problem. The number of generations = 300 is initially taken into account to conduct the experiment.

In the genetic search process, the following parameter values are introduced.

- probability of crossover $P c=0.8$

- probability of mutation $P m=0.08$

- population size $=100$

- chromosome length $=150$.

The GA-based programme is designed in Programming Language $\mathrm{C}++$. The execution is done in an Intel Pentium IV with $2.66 \mathrm{GHz}$ clock-pulse and $1 \mathrm{~GB}$ RAM. The optimal solution is reached at 200 generations.

The model solution is presented in the Table 5 .

Table 5. Land Allocation and Crops Production under the Proposed Model

\begin{tabular}{|ccc|}
\hline Crop (c) & Land Allocation & Production \\
\hline Jute & 123.37 & 332.27 \\
Sugarcane & 1.9 & 149.46 \\
Rice & 334.72 & 896.38 \\
Wheat & 55.05 & 117.34 \\
Mustard & 87.15 & 78.56 \\
Potato & 5.5 & 147.50 \\
Pulses & 49.95 & 41.55 \\
\hline
\end{tabular}

The total profit obtained under the proposed cropping plan is Rs. 110299.47 Lac.

The land allocation and production structure of the existing cropping plan (2005-2006) is presented in the Table 6.

Table 6. Land Allocation and Crops Production Recorded in the Year 2005-2006

\begin{tabular}{|ccc|}
\hline Crop (c) & Land Allocation & Production \\
\hline Jute & 120.20 & 325.15 \\
Sugarcane & 1.50 & 118.00 \\
Rice & 265.40 & 732.40 \\
Wheat & 47.10 & 100.40 \\
Mustard & 79.20 & 71.40 \\
Potato & 5.50 & 147.50 \\
Pulses & 46.40 & 38.60 \\
\hline
\end{tabular}

Here, the achieved annual profit is Rs. 95803.01 Lac.

\section{PERFORMANCE COMPARISON}

From the above discussion and solution comparisons, it may be claimed that the proposed approach is superior over the existing crop production plan with regard to proper allocation of productive resources and thereby arriving at the most satisfactory cropping plan with regard to the needs and desires of the DM in the farm management and planning horizon.
A comparison of the model solution with the result in the Table 6 shows that a satisfactory decision for the optimal cropping plan is obtained here in the decision making environment.

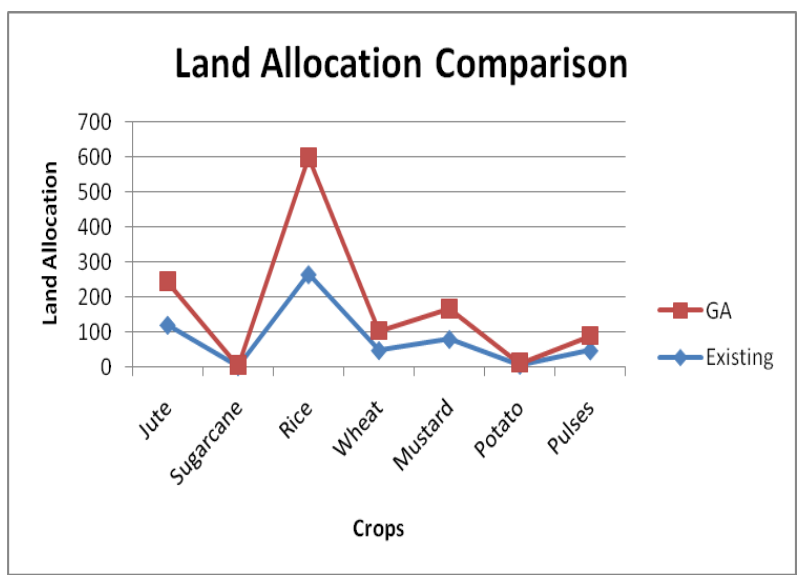

Fig 1: Pictorial representation of land allocation comparison

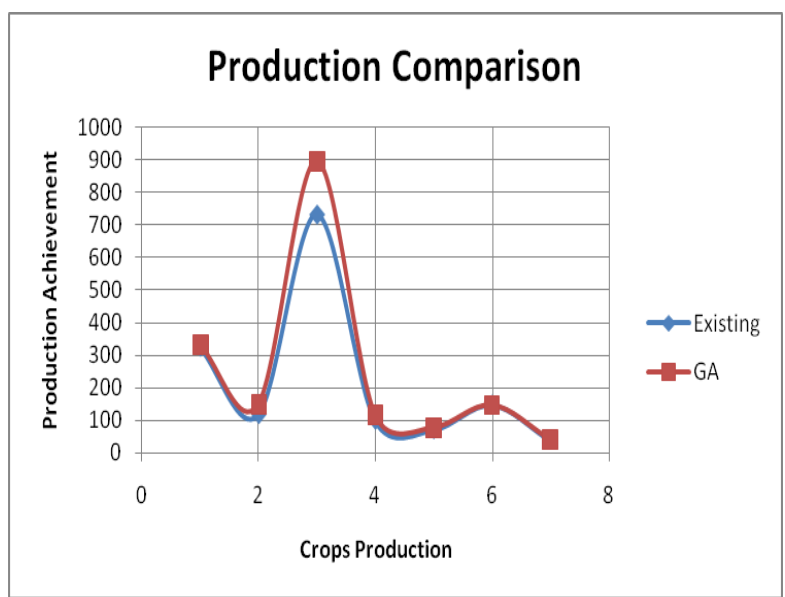

Fig 2: Pictorial representation of production comparison

The following Figure represents diagrammatically the profit achievements under the existing plan and the proposed FGP based GA approach.

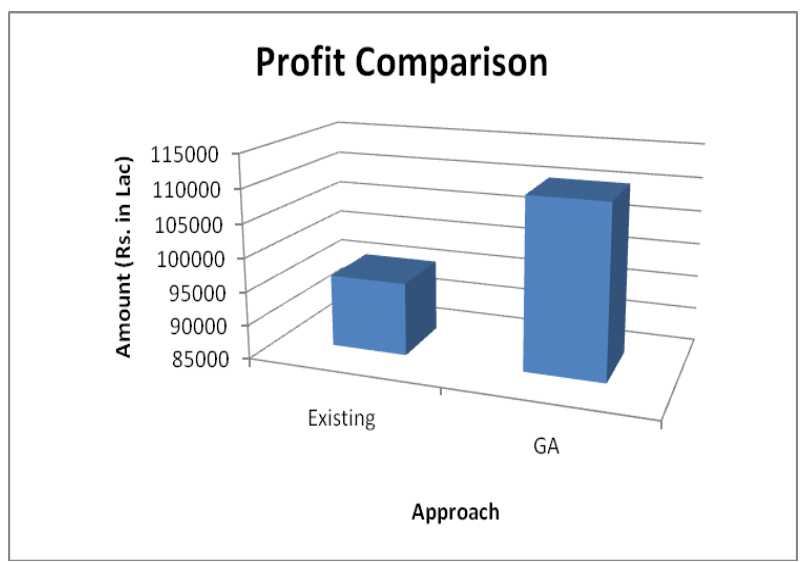

Fig 3: Pictorial representation of profit comparison

\section{CONCLUSION}

In the framework of proposed approach, the other different parameters (fuzzy / probabilistic) can easily be incorporated 
without involving any computational difficulty. In future studies, the proposed approach can be extended to cropping plan problems having the fuzzy satisficing probability levels of the chance constraints in the decision situation.

Further, since GAs are population based global solution search methods, the efficient use of an GA scheme to the proposed MODM problem always offers a satisfactory decision in the context of farm management for seasonal cropping plan.

Finally, it is hoped that the solution concept presented here can contribute to future studies in farming and other stochastic MODM problems in the current uncertain decision making arena.

\section{ACKNOWLEDGMENTS}

The author is thankful to the anonymous Reviewers of IJCA for their valuable comments and suggestions which have led to improve the quality and clarity of presentation of the research paper.

\section{REFERENCES}

[1] Romero, C. 1986 A Survey of Generalized Goal Programming, European Journal of Operational Research, Vol. 25, No. 2, 183 - 191.

[2] Glen, J. 1987 Mathematical Models in Farm Planning: A Survey, Operations Research, Vol. 35, 641 - 666

[3] Pal, B. B. and Basu. I. 1996 Selection of Appropriate Priority Structure for Optimal Land Allocation in Agricultural Planning through Goal Programming, Indian Journal of Agricultural Economics, Vol. 51, 342 - 354

[4] Zimmermann, H. -J. 1978 Fuzzy Programming and Linear Programming with Several Objective Functions, Fuzzy Sets and Systems, Vol. 1, No. 1, 45-55.

[5] Pal, B.B. and Chakraborti D. 2013 Using Genetic Algorithm for Solving Quadratic Bilevel Programming Problems via Fuzzy Goal Programming, International Journal of Applied Management Science, Vol. 5, No.2, 172-195.

[6] Pal, B.B. and Moitra, B. N. 2004 Using fuzzy goal programming for long range production planning in agricultural systems, Indian Journal of Agricultural Economics, Vol. 59, No. 1, 75 - 90.

[7] Pal, B.B., Chakraborti D. and Biswas, P. 2009 A Genetic Algorithm Based Hybrid Goal Programming Approach to Land Allocation Problem for Optimal Cropping Plan in Agricultural System, Proceedings of $4^{\text {th }}$ International Conference on Industrial and Information Systems (ICIIS) 2009, EICS 1-4, 1-6, Published in IEEE Xplore Digital Library.
[8] Charnes, A. and Cooper, W.W. 1959 Chance-constrained Programming, Management Science, Vol. 6, 73-79.

[9] Feiring, B.R., Sastri, T and Sim, I.S.M. 1998 A Stochastic Programming Model for Water Resource Planning, Mathematical Computer Modeling, Vol. 27, No. 3, 1-7.

[10] Hulsurkar, S., Biswal, M.P. and Sinha, S.B. 1997 Fuzzy Programming Approach to Multi-objective Stochastic Linear Programming Problems, Fuzzy Sets and Systems, Vol. 88, 173-181.

[11] Luhandjula, M.K. 1984 Fuzzy Approaches for Multiple Objective Liaanear Fractional Optimization, Fuzzy Sets and Systems, Vol. 13, No. 1, $11-23$.

[12] Pal, B. B., Moitra, B. N. and Maulik, U. 2003 A Goal Programming Procedure for Fuzzy Multiobjective Linear Fractional Programming Problems, Fuzzy Sets and Systems, Vol. 139, 395 - 405 .

[13] Tiwari, R.N., Dharmar, S. and Rao, J.R. 1987 Fuzzy Goal Programming - an Additive Model, Fuzzy Sets and Systems, Vol. 24, 27-34

[14] Holland, J.H. 1973 Genetic Algorithms and optimal allocation of trial, SIAM Journal of Computing, Vol. 2, No. 2, 88 - 105 .

[15] Deb， K. 2002 Multi-objective Optimization using Evolutionary Algorithms, John Wiley \& Sons Ltd.

[16] Govt. of W. B., India. 2006. District Statistical Hand Book, Nadia, Department of Bureau of Applied Economics and Statistics.

[17] Govt. of W. B., Action Plan for the year 2004-2005 and 2005-2006, Office of the Principal Agricultural Officer, Nadia, India.

[18] Basak, R. K. 2000 Soil Testing and Fertilizer Recommendation, Kalyani Publishers, New Delhi

[19] Govt. of W. B., Department of Agri-irrigation, Office of the Executive Engineer, Krishnanagar, Nadia, India.

[20] Zimmermann, H.-J. 1987 Fuzzy Sets, Decision Making and Expert Systems, Kluwer Academic Publisher.

[21] Goldberg, D.E. 1989 Genetic Algorithms in Search, Optimization, and Machine Learning. Addison-Wesley, Reading. MA. 